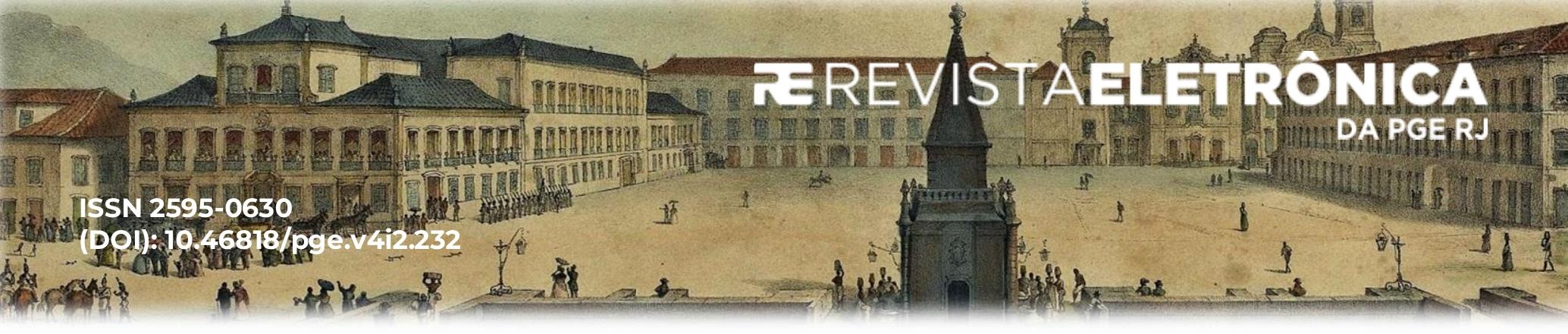

\title{
PROTEÇÃO DE CRIANÇAS E ADOLESCENTES NA LGPD: desafios interpretativos
}

\author{
CHILDREN PROTECTION IN THE BRAZILIAN GENERAL DATA PROTECTION \\ LAW: interpretative challenges
}

\author{
Elora Fernandes ${ }^{1}$ \\ Filipe Medon ${ }^{2}$
}

\begin{abstract}
RESUMO: A Lei Geral de Proteção de Dados Pessoais (LGPD), desde a sua promulgação, é objeto de diversas discussões doutrinárias acerca de alguns de seus dispositivos. No que se refere à proteção especial de crianças e adolescentes, disposta no art. 14, da Lei, percebe-se que ainda persistem dúvidas interpretativas e lacunas regulatórias que, diante do tratamento massivo de dados pessoais, podem ser prejudiciais ao melhor interesse. A partir disso, este trabalho busca discutir quatro pontos ainda obscuros na Lei acerca da temática, quais sejam, a normativa referente ao consentimento; as bases legais aplicáveis ao tratamento de dados de crianças e adolescentes; a necessidade da elaboração do Relatório de Impacto à Proteção de Dados como instrumento para proteção da privacidade e dos dados de crianças e adolescentes; e, o debate acerca da efetivação da norma constante do art. $14, \S^{\circ}$, da LGPD.
\end{abstract}

PALAVRAS-CHAVE: Proteção de dados. Privacidade. Crianças e adolescentes. Lei Geral de Proteção de Dados Pessoais (LGPD).

ABSTRACT: Since its enactment, there has been several doctrinal discussions about some provisions of the Brazilian General Data Protection Law. Regarding the necessity of children's special protection in its article 14, there are still interpretative questions and regulatory gaps that, given the massive processing of personal data, can be harmful to the best interest of the child. This paper seeks to discuss four points that are still obscure in the law about the theme, namely, the normative referring to consent; the legal bases applicable to processing of children's data; the need to conduct a Data Protection Impact Assessment as an instrument to protect children's data and privacy; and the debate about the implementation of the rule contained in the law's art. $14, \S 4$.

KEYWORDS: Data protection. Privacy. Children. Brazilian General Data Protection Regulation.

\footnotetext{
${ }^{1}$ Doutoranda em Direito Civil pela Universidade do Estado do Rio de Janeiro (UERJ). Mestra em Direito e Inovação pela Universidade Federal de Juiz de Fora (UFJF) e graduada em Direito pela mesma instituição, com período de intercâmbio acadêmico na Universidad de Salamanca (Espanha). Faz parte do corpo editorial da Revista de Estudos Empíricos em Direito (REED) e é alumna do Deutscher Akademischer Austauschdienst (DAAD). Email: elorafernandes@live.com.

${ }^{2}$ Doutorando e Mestre em Direito Civil pela Universidade do Estado do Rio de Janeiro (UERJ). Professor Substituto de Direito Civil na Universidade Federal do Rio de Janeiro (UFRJ) e de cursos de Pós-Graduação do Instituto New Law, PUC-Rio, IERBB-MP/RJ, ESA-OAB, CEPED-UERJ, EMERJ, CEDIN, CERS e do Curso Trevo. Membro da Comissão de Proteção de Dados e Privacidade da OAB-RJ, do Instituto Brasileiro de Estudos de Responsabilidade Civil (IBERC) e do Instituto Brasileiro de Direito de Família (IBDFAM). Advogado e pesquisador. Instagram: @ filipe.medon.
} 
SUMÁRIO: Introdução. 1. Consentimento e autoridade parental; 2. Bases legais para o tratamento de dados de crianças e adolescentes; 3. Relatório de Impacto à Proteção de Dados; 4. A Minimização na coleta dos dados segundo o artigo 14, §4º; Conclusão.

SUMMARY: Introduction. 1. Consent and parental authority; 2. Legal basis for processing children's data; 3. Data Protection Impact Assessment; 4. Data minimization according to article 14, §4; Conclusion.

\section{Introdução}

Desde antes da sua promulgação e entrada em vigor, a Lei Geral de Proteção de Dados Pessoais (Lei $\mathrm{n}^{\circ}$. 13.709/2018) já era objeto de intensos e inquietantes debates doutrinários acerca do sentido e do alcance de alguns de seus dispositivos. Passados mais de dois anos, parece ainda não haver consenso com relação a alguns deles, como é o caso do regime de responsabilidade civil que teria sido adotado pela Lei e a disciplina protetiva de crianças e adolescentes conferida pelo polêmico artigo 14 .

A inquietação neste último caso se revela especialmente problemática, sobretudo quando se tem em vista a necessidade de se conferir tutela protetiva diferenciada a essas pessoas em desenvolvimento e marcadamente vulneráveis. A lesão a seus direitos da personalidade, em que se pode incluir a proteção de sua privacidade e, mais amplamente, de seus dados pessoais, tem a potencialidade de causar danos permanentes que, se ainda não se revelam no presente, por certo serão manifestados num futuro próximo. ${ }^{3}$

Para se ter uma dimensão disso, basta pensar que dados coletados hoje por meio, por exemplo, de redes sociais, aplicativos diversos e brinquedos inteligentes conectados à Internet (Internet of Toys), poderão vir a formar os perfis dos adultos de amanhã e de forma às vezes irreversível, dada a dificuldade em se exercer o arrependimento no futuro. ${ }^{4} \mathrm{Se}$ a perfilização

\footnotetext{
3 "Vale lembrar que o desenvolvimento cognitivo e mental do ser humano inicia-se na infância e é um processo identificável que se dá por várias etapas e superação de fase subsequentes na sequência correta, sem que seja possível pular estágios. Não se trata de algo que se adquire e transforma-se em um patrimônio do indivíduo, mas é uma evolução, uma construção paulatina, que demanda tempo e vivências, atreladas a uma interação complexa e multirreferencial entre a natureza da constituição genética (nature) e os estímulos dos meios de convivência e socialização da criança (nurture), inclusive os provenientes das novas tecnologias de informação e comunicação. O sentimento de vergonha, por exemplo, não é identificado em bebês com menos de dois anos. Da mesma forma, a autonomia faz parte do desenvolvimento humano, seja do ponto de vista motor e corporal, seja do ponto de vista afetivo, moral e intelectual." (HARTUNG, Pedro; HENRIQUES, Isabella; PITA, Marina. A proteção de dados pessoais de crianças e adolescentes. In: DONEDA, Danilo; MENDES, Laura Schertel; SARLET, Ingo Wolfgang; RODRIGUES JR., Otavio Luiz; BIONI, Bruno (coords). Tratado de Proteção de Dados Pessoais. Rio de Janeiro: Forense, 2021, pp. 204-205).

${ }^{4}$ A esse respeito, permita-se a referência a: TEPEDINO, Gustavo; MEDON, Filipe. A superexposição de crianças por seus pais na internet e o direito ao esquecimento. No prelo.
} 
(profiling) $)^{5}$ com base em dados pessoais já é perigosa para adultos, o que dizer de dados que são coletados desde a mais tenra infância, ${ }^{6}$ e que poderão ser utilizados para as mais diversas finalidades no futuro? Como exercer o controle desses dados? É certo que o risco de manipulação e classificação dessas pessoas "deve ser combatido para que, no exercício de seu direito à privacidade, eles possam ser livres para escolher serem eles mesmos, consumir o que bem entenderem e trilhar suas trajetórias livremente."7

A importância de se atentar para o tratamento dos dados dessas pessoas em desenvolvimento pode ser avaliada a partir dos múltiplos impactos e problemas para o bemestar individual e social, como, por exemplo:

(i) a ameaça à integridade física, psíquica e moral por contatos maliciosos de terceiros; (ii) a hiperexposição de dados pessoais e discriminação; (iii) a modulação e manipulação de comportamento; e (iv) a microssegmentação da prática abusiva e ilegal da publicidade infantil. ${ }^{8}$

A partir da leitura de seu artigo 14, percebe-se que a LGPD não abrangeu todos os desafios que se apresentam no tratamento de dados de crianças e adolescentes e, no que se refere àquilo que foi regulado, há ainda diversas dúvidas interpretativas. Dentre elas, pode-se destacar quatro eixos, os quais serão objeto de análise deste artigo: primeiramente, é preciso delimitar a normativa aplicável ao consentimento, seja para saber quem precisa consentir, seja para saber a extensão da autonomia conferida às crianças e aos adolescentes. Em segundo lugar, discutese quais seriam as bases legais aplicáveis ao tratamento de dados desses sujeitos, vez que o art. 14 traz normativas específicas apenas para o consentimento. Em um terceiro momento, buscase compreender a importância da elaboração do Relatório de Impacto à Proteção de Dados como instrumento para proteção da privacidade e dos dados de crianças e adolescentes. E, finalmente, é apresentado o debate acerca da efetivação da norma constante do art. 14, §4 ${ }^{\circ}$, da LGPD, à luz

\footnotetext{
${ }^{5}$ DONEDA, Danilo. Da privacidade à proteção de dados pessoais, Rio de Janeiro: Renovar, 2006, p. 173.

${ }^{6} \mathrm{O}$ desafio aqui é ainda maior se considerado o fato de que "as crianças e os adolescentes atuais são a primeira geração cujos dados estão armazenados desde o nascimento, razão pela qual o cuidado tem que ser maior, em face da própria novidade do tema." (TEIXEIRA, Ana Carolina Brochado; RETTORE, Anna Cristina de Carvalho. A autoridade parental e o tratamento de dados pessoais de crianças e adolescentes. In: TEPEDINO, Gustavo; FRAZÃO, Ana; OLIVA, Milena Donato (coords.). Lei Geral de Proteção de Dados Pessoais e suas repercussões no Direito Brasileiro. São Paulo: Thomson Reuters Brasil, 2019, p. 517).

7 TEIXEIRA, Ana Carolina Brochado; RETTORE, Anna Cristina de Carvalho. A autoridade parental e o tratamento de dados pessoais de crianças e adolescentes. In: TEPEDINO, Gustavo; FRAZÃO, Ana; OLIVA, Milena Donato (coords.). Lei Geral de Proteção de Dados Pessoais e suas repercussões no Direito Brasileiro. São Paulo: Thomson Reuters Brasil, 2019, p. 517.

${ }^{8}$ HARTUNG, Pedro; HENRIQUES, Isabella; PITA, Marina. A proteção de dados pessoais de crianças e adolescentes. In: DONEDA, Danilo; MENDES, Laura Schertel; SARLET, Ingo Wolfgang; RODRIGUES JR., Otavio Luiz; BIONI, Bruno (coords). Tratado de Proteção de Dados Pessoais. Rio de Janeiro: Forense, 2021, p. 203.
} 
da realidade fática de contratações de adesão e da necessidade de se prevenir a exploração dos dados infanto-juvenis para além do estritamente necessário para o funcionamento de determinada aplicação. É disso que se passa a tratar.

\section{Consentimento e autoridade parental}

Oriundo do vocábulo latino consentire, etimologicamente, o verbo "consentir" quereria dizer "sentir junto". Talvez esta busca etimológica revele um conceito oculto que o legislador, embora não tenha pensado, pode ter alcançado por meio da disciplina do parágrafo primeiro do artigo 14, quando dispôs que: “[o] tratamento de dados pessoais de crianças deverá ser realizado com o consentimento específico e em destaque dado por pelo menos um dos pais ou pelo responsável legal."

Fato é que, numa primeira leitura, a superfície do dispositivo parece indicar que como as crianças são encaradas pela legislação como absolutamente incapazes de praticar por si só os atos da vida civil, caberá a pelo menos um dos pais ou responsável legal consentir para que haja o tratamento de seus dados pessoais, que, por força do caput do mesmo artigo, deverá ser realizado em seu melhor interesse.

Nada obstante, para além da camada superficial do dispositivo, um mergulho mais profundo em sua teleologia permite conduzir o intérprete à exegese de que o tanto quanto possível é preciso que os pais "sintam junto" de seus filhos. Dito em outras palavras: o consentimento passa a ser encarado numa perspectiva dialógica, que considera e tem como base a autonomia crescente daquela pessoa em desenvolvimento.

Não é por outro motivo que o legislador deliberadamente excluiu o adolescente da regra insculpida no parágrafo primeiro do artigo. E o que está por trás disso é justamente essa percepção de que deve ser considerada a autonomia do adolescente, cuja predominância é diretamente proporcional ao desenvolvimento de suas capacidades para assumir os encargos de sua vida na rede e fora dela a partir de uma atuação dialógica dos pais.

Tal participação na idade zero é total. São os pais que tomam todas as decisões relativas aos dados pessoais de seus filhos, quando estas dependem do consentimento, como a catalogação de seu crescimento por meio de aplicativos de acompanhamento da gravidez ou de seu cadastro em hospitais, escolas etc. Conforme a criança vai crescendo, ela passa a "sentir junto" com seus pais, manifestando também seus desejos e vontades, que devem ser respeitados dentro do possível. Finalmente, quando ingressam na adolescência, o papel dos pais começa a 
diminuir: o protagonismo no consentimento passa a ser cada vez mais dos adolescentes.

Como se afirmou em outra sede:

\begin{abstract}
Isso porque a criação e a educação dos filhos ocorrem como um processo: tanto maior é a atuação dos pais quanto menor são os filhos, ou melhor, quanto menos discernimento eles têm. Quando vão crescendo, automaticamente faz-se menos necessária a intervenção parental, vez que, através desta mesma convivência e do processo educacional, vivenciam situações que lhes conduzem à paulatina aquisição da maturidade. Dessa forma, vão se tornando mais aptos para o exercício dos direitos fundamentais, fazendo opções com mais liberdade. ${ }^{9}$
\end{abstract}

Isso não significa dizer, contudo, que os pais se exoneram de suas responsabilidades: a autoridade parental, verdadeiro múnus, os obriga a participar ativamente da tomada de decisão dos filhos na rede por meio daquilo que a doutrina tem chamado de "educação digital", em contraposição direta ao que se convencionou designar por "abandono digital". ${ }^{10} \mathrm{E}$, assim, dever precípuo dos pais orientar e supervisionar os filhos, ainda que lhes garantindo um espaço mínimo (que aumenta com a idade) de privacidade e intimidade ${ }^{11}$ para o livre desenvolvimento de suas personalidades.

Todavia, há que se ressaltar a diminuta importância do consentimento na realidade, sobretudo quando considerado o fato de que, usualmente, "os pais não têm controle sobre a atividade de seus filhos em ambientes virtuais e em situações que impliquem coleta de dados. Algumas vezes, as crianças podem forjar o consentimento parental para terem acesso a conteúdo e aplicativos que sejam de seu interesse."12

\footnotetext{
${ }^{9}$ TEIXEIRA, Ana Carolina Brochado; MEDON, Filipe. A hipersexualização infanto-juvenil na internet e o papel dos pais: liberdade de expressão, autoridade parental e melhor interesse da criança, p. 08. No prelo.

10 TEIXEIRA, Ana Carolina Brochado. NERY, Maria Carla Moutinho. Vulnerabilidade digital de crianças e adolescentes: a importância da autoridade parental para uma educação nas redes. In: EHRHARDT JR., Marcos; LOBO, Fabíola (orgs.). Vulnerabilidade e sua compreensão no direito brasileiro. Indaiatuba: Foco, 2021, p. 142. ${ }^{11}$ Por mais, ver: SHMUELI, Benjamin; BLECHER-PRIGAT, Ayelet. Privacy for Children. Columbia Human Rights Law Review, [s.1.], v. 42, p. 759-795, 2011. Disponível em: https://papers.ssrn.com/sol3/papers.cfm?abstract_id=1746540. Acesso em: 13 fev. 2021., p. 761.

12 EBERLIN, Fernando Büscher von Teschenhausen. Direitos da Criança na Sociedade da Informação: ambiente digital, privacidade e dados pessoais. São Paulo: Thomson Reuters Brasil, 2020, p. 206. Nesse sentido, pode-se destacar o caso da menina italiana de 10 anos, que morreu, em janeiro de 2021, após suposta participação no Blackout Challenge no TikTok, que consiste em estar o maior tempo possível sem respirar. A Autoridade italiana proibiu a rede social de continuar a processar dados de usuários dos quais não se tem certeza da idade, o que violaria as disposições relacionadas ao tratamento de dados de crianças e adolescentes no país. Ela já tinha aberto, inclusive, um processo contra o TikTok em dezembro, alegando uma falta de atenção à proteção de crianças e criticando a facilidade com que elas conseguem se inscrever na plataforma (ITALY blocks TikTok for certain users after death of girl allegedly playing 'choking' game. The Guardian. [s.l.]. 23 jan. 2021. Disponível em: https://www.theguardian.com/world/2021/jan/23/italy-blocks-tiktok-for-certain-users-after-death-of-girlallegedly-playing-choking-game. Acesso em: 12 fev. 2021. ITÁLIA. GARANTE PER LA PROTEZIONE DEI DATI PERSONALI. Tik Tok: dopo il caso della bimba di Palermo, il Garante privacy dispone il blocco del social. 2021. Disponível em: https://www.garanteprivacy.it/web/guest/home/docweb//docweb-display/docweb/9524224. Acesso em: 12 fev. 2021. ITÁLIA. GARANTE PER LA PROTEZIONE DEI DATI PERSONALI. Tik Tok, $a$
} 


\section{Como esclarece Fernando Eberlin:}

mesmo que o consentimento seja formalizado pelos pais, eles possivelmente não acompanharão os filhos na utilização dos serviços e terão pouca ou nenhuma influência em relação aos conteúdos acessados, à forma de utilização e aos dados efetivamente fornecidos pelas crianças. Vale dizer, ainda que o consentimento parental seja verificável (como requerem a LGPD e o COPPA), o fato de a mãe ou o pai consentirem não significa que a criança estará preparada. ${ }^{13}$

Nessa direção, apesar da intensa controvérsia ${ }^{14}$ que se coloca na doutrina e ainda que não tenha sido a melhor solução, vez que não houve qualquer estudo empírico sobre as habilidades digitais das crianças brasileiras no desenvolvimento da Lei, o legislador parece ter sido claro ao criar no parágrafo primeiro, do art. 14, hipótese de capacidade especial para os adolescentes com relação à manifestação de seu consentimento para o tratamento de seus dados pessoais, optando "por considerar jurídica e legítima situação dotada de ampla aceitação social." $" 15$

rischio la privacy dei minori: il Garante avvia il procedimento contro il social network, il Garante privacy dispone il blocco del social. 2021. Disponível em: https://www.garanteprivacy.it/web/guest/home/docweb/-/docwebdisplay/docweb/9508923. Acesso em: 12 fev. 2021.).

${ }^{13}$ EBERLIN, Fernando Büscher von Teschenhausen. Direitos da Criança na Sociedade da Informação: ambiente digital, privacidade e dados pessoais. São Paulo: Thomson Reuters Brasil, 2020, pp. 206-207.

14 “[a]inda que o $\S 1^{\circ}$ não mencione os adolescentes, não faria sentido deixá-los desprovidos da igual e devida proteção, sob pena de se violar as garantias constitucionais dessas pessoas. Há que se defender, nesse caso, a aplicação do Código Civil, a fim de se promover a integralidade de seus direitos. De fato, a proteção de dados pessoais, entendida enquanto parte do contrato civil, reforça a objeção à capacidade legal de crianças e de adolescentes consentirem quanto ao tratamento de seus dados, uma vez que, pelo exercício do poder familiar, compete a mães, pais e responsáveis representá-los até os 16 anos, nos atos da vida civil, e assisti-los, após essa idade, nos atos em que forem partes, suprindo-lhes o consentimento. Não se coadunaria, com efeito, com as garantias legais ao melhor interesse e à absoluta prioridade do adolescente que lhe fosse facultada a outorga de consentimento autônomo limitado para o tratamento de seus dados pessoais. Dessa forma, entende-se indispensável o consentimento parental ou de pessoa responsável legal para o tratamento de dados pessoais de crianças e de adolescentes de até 16 anos de idade, observando-se a forma prevista no referido $14, \S 1^{\circ}$, da LGPD, devendo, assim, o consentimento ser específico e em destaque. No caso de adolescentes entre 16 e 18 anos, será necessário o consentimento de ambos, não bastando o consentimento parental." (HARTUNG, Pedro; HENRIQUES, Isabella; PITA, Marina. A proteção de dados pessoais de crianças e adolescentes. In: DONEDA, Danilo; MENDES, Laura Schertel; SARLET, Ingo Wolfgang; RODRIGUES JR., Otavio Luiz; BIONI, Bruno (coords). Tratado de Proteção de Dados Pessoais. Rio de Janeiro: Forense, 2021, pp. 212-213); TEPEDINO, Gustavo; TEFFÉ, Chiara Spadaccini de. Consentimento e proteção de dados pessoais na LGPD. In: TEPEDINO, Gustavo; FRAZÃO, Ana; OLIVA, Milena Donato (coords.). Lei Geral de Proteção de Dados Pessoais e suas repercussões no Direito Brasileiro. São Paulo: Thomson Reuters Brasil, 2019, p. 313; TEIXEIRA, Ana Carolina Brochado; RETTORE, Anna Cristina de Carvalho. A autoridade parental e o tratamento de dados pessoais de crianças e adolescentes. In: TEPEDINO, Gustavo; FRAZÃO, Ana; OLIVA, Milena Donato (coords.). Lei Geral de Proteção de Dados Pessoais e suas repercussões no Direito Brasileiro. São Paulo: Thomson Reuters Brasil, 2019, p. 526; "Se, por um lado, a idade de 12 anos pode parecer muito baixa, desprotegendo jovens de 13 e 14 anos, talvez, por outro lado, seja irreal pensar que a coleta de dados de adolescentes de 17 anos se submeta ao consentimento dos pais. Daí a eleição pela norma europeia de um marco de 16 anos - exemplo que poderia ter sido seguido pelo legislador brasileiro." (SCHREIBER, Anderson. Proteção de dados no Brasil e na Europa. Carta Forense. [s.l.]. 5 set. 2018. Disponível em: http://www.cartaforense.com.br/conteudo/colunas/protecao-de-dadospessoais-no-brasil-e-na-europa/18269. Acesso em: $13 \mathrm{fev}$. 2021.).

${ }^{15}$ E prossegue a autora: "Vale lembrar, inclusive, que tanto o Código Civil quanto o Estatuto da Criança e do 
Outro argumento que serve como sustentáculo a esta linha argumentativa reside na empiria: o $§ 5^{\circ}$, do artigo 14, obriga o controlador a realizar todos os esforços razoáveis para verificar que o consentimento a que se refere o $\S 1^{\circ}$ foi dado pelo responsável pela criança, consideradas as tecnologias disponíveis Todavia, a dificuldade nessa apuração concreta, sobretudo diante de uma realidade social dinâmica em que crianças e adolescentes usam o celular sozinhas cada vez mais cedo, torna extremamente difícil o consentimento válido dos pais em relação às atividades dos adolescentes. ${ }^{16} \mathrm{E}$ o que poderia ser convite para caudalosas críticas, em verdade, revela-se como oportunidade para uma compreensão mais ampla, tanto do papel da autoridade parental na inserção responsável dos filhos no ambiente digital quanto do papel essencial de regulação e proteção por parte do Estado e de sociedades empresárias.

A partir disso, a autoridade parental precisa ser revisitada, com especial atenção para seus limites (conteúdos negativos) e deveres (conteúdos positivos). Dentre os limites, pode-se destacar a prática conhecida como (over)sharenting, que consistiria na superexposição na rede de dados e da imagem de crianças e adolescentes por quem mais deveria protegê-las: seus pais (ou, ainda, parentes próximos). ${ }^{17}$ Aqui, os riscos são imensos, como se teve a oportunidade de destacar em outras sedes, incluindo a apropriação da narrativa da história de vida dos filhos pelos pais, o roubo de identidade por criminosos e a construção de perfis que serão posteriormente utilizados por mecanismos de tomada automatizada de decisões por Inteligência Artificial, bem como para bombardeamento de publicidade e propaganda político-ideológica. ${ }^{18}$ Igualmente importantes são os conteúdos positivos desse múnus: mais do que

\footnotetext{
Adolescente trazem em suas normas determinadas disposições que valorizam a vontade dos menores e oferecem hipóteses de capacidade especial a eles. (...) Essa norma, sem dúvida, pode ser interpretada como uma exceção ao regime de incapacidade civil. Contudo, seria ela realmente benéfica ao sujeito a quem faz referência?" (TEFFÉ, Chiara Spadaccini de. Tratamento de dados pessoais de crianças e adolescentes: considerações sobre o artigo 14 da LGPD. O tratamento de dados pessoais sensíveis. In: MULHOLLAND, Caitlin (org.). A LGPD e o novo marco normativo no Brasil. Porto Alegre: Arquipélago, 2020, pp. 166-167).

${ }^{16}$ Acerca de ferramentas para a verificação da idade no ambiente virtual, cf. nota de rodapé $n^{\circ} 40$.

${ }^{17}$ Por mais, recomenda-se: STEINBERG, Stacey. Growing up shared: how parents can share smarter on social media - and what you can do to keep your family safe in a no-privacy world. Naperville: Sourcebooks, 2020; BLUM-ROSS, Alicia; LIVINGSTONE, Sonia. "Sharenting," parent blogging, and the boundaries of the digital self. Popular Communication, [s.1.], v. 15, n. 2, p. 110-125, 3 abr. 2017. Informa UK Limited. http://dx.doi.org/10.1080/15405702.2016.1223300; BROSCH, Anna. When the child is born into the internet: sharenting as a growing trend among parents on facebook. The New Educational Review, [s.1.], v. 43, n. 1, p. 225235, 31 mar. 2016. Wydawnictwo Adam Marszalek. http://dx.doi.org/10.15804/tner.2016.43.1.19; EBERLIN, Fernando Büscher von Teschenhausen. Sharenting, liberdade de expressão e privacidade de crianças no ambiente digital: o papel dos provedores de aplicação no cenário jurídico brasileiro. Revista Brasileira de Políticas Públicas, [s.1.], v. 7, n. 3, p. 256-274, 6 fev. 2018. Centro de Ensino Unificado de Brasília. http://dx.doi.org/10.5102/rbpp.v7i3.4821..

${ }^{18}$ TEPEDINO, Gustavo; MEDON, Filipe. A superexposição de crianças por seus pais na internet e o direito ao esquecimento. No prelo; MEDON, Filipe. (Over)sharenting: a superexposição da imagem e dos dados da criança na internet e o papel da autoridade parental. In: TEIXEIRA, Ana Carolina Brochado; DADALTO, Luciana. Autoridade Parental: dilemas e desafios contemporâneos. Indaiatuba: Editora Foco, 2021, 2. ed.
} 
providenciar moradia, alimento, respeito, saúde e educação, a autoridade parental também impõe, na realidade atual, a participação ativa dos pais nesse processo de ambientação da criança e do adolescente à realidade tecnológica que os circunda. $\mathrm{O}$ primeiro passo, certamente, há de ser garantir o acesso da criança à tecnologia, pois a desigualdade social ainda não tem permitido o acesso amplo, o que é tarefa compartilhada entre pais e também o Estado. ${ }^{19}$

Todavia, apesar da importância fundamental da participação dos pais ou responsáveis na proteção da privacidade e dos dados pessoais daqueles que estão sob sua tutela, há que se atentar, também, para a atuação do setor privado e do governo na construção desse rastro digital. Primeiramente, pois o consentimento é apenas uma das bases legais que permitem o tratamento de dados de crianças e adolescentes e, hoje, é cada vez menos utilizado. Em segundo lugar, diversos são os estudos que questionam a racionalidade humana na tomada de decisões, especialmente quando os custos de transação para agir de forma diferente são altos, como no caso da leitura de enormes e difíceis Termos de Uso e da possibilidade de não utilização de serviços hoje essenciais. ${ }^{20}$ Isso é especialmente problemático nas redes sociais, cujos modelos de negócio dependem da agregação de uma quantidade gigantesca de dados e incentivam o compartilhamento excessivo de informações — inclusive de crianças.

Por fim, dados de crianças e adolescentes estão cada vez mais sendo tratados de forma agregada aos dados de suas famílias. ${ }^{21}$ Esse é o caso dos objetos conectados e assistentes virtuais, que tratam dados de várias pessoas ao mesmo tempo, inclusive crianças e adolescentes, sem que necessariamente o melhor interesse tenha sido levado em consideração na construção dessas tecnologias.

A partir dessas reflexões, apesar do reconhecimento de que os adultos também precisam ter e oferecer boa educação digital, é necessário trazer outros atores para a discussão, evitando colocar exclusivamente sobre os ombros dos pais ou responsáveis a culpa e o fardo de todos os riscos do tratamento de dados de crianças e adolescentes. A fim de concretizar o artigo 227, da Constituição Federal, que aponta como sendo dever de todos os atores da sociedade a proteção

\footnotetext{
${ }^{19}$ Para uma análise específica sobre as dificuldades da utilização da base legal do consentimento na realidade brasileira, extremamente desigual, cf. FERNANDES, Elora. Tratamento de dados de adolescentes no Brasil e a necessária proteção de direitos por design. In: Instituto de Tecnologia e Sociedade (ITS). Trabalhos finais do Grupo de Pesquisa 2020. Disponível em em: https://itsrio.org/wp-content/uploads/2020/10/Tratamento-de-dadosde-adolescentes-no-Brasil-e-a-necessária-proteção-de-direitos-por-design_Elora_Fernandes.pdf.

${ }^{20}$ Cf. FERNANDES, Elora Raad. Direitos de crianças e adolescentes por design: uma agenda regulatória para a ANPD. In: LATERÇA, Priscilla Silva; FERNANDES, Elora; TEFFÉ, Chiara de; BRANCO, Sérgio. Privacidade e Proteção de Dados de Crianças e Adolescentes. Rio de Janeiro: Obliq, 2021.

${ }^{21}$ BARASSI, Veronica. Child $\mid$ Data $\mid$ Citizen: how tech companies are profiling us from before birth. Cambridge: Mit Press, 2020.
} 
dos direitos de crianças e adolescentes, incluindo sociedades empresárias e Estado, é imprescindível cobrar destes uma atitude proativa na construção de regulações e tecnologias que protejam dados desde a sua concepção.

\section{Bases legais para o tratamento de dados de crianças e adolescentes}

Tendo em vista a polêmica relacionada ao consentimento já explicitada no capítulo anterior, pouco se discutiu, até a entrada em vigor da LGPD, acerca das bases legais que poderiam ser utilizadas para se tratar dados de crianças e adolescentes. A Lei não apresenta regra explícita sobre o tema e, por isso, é necessário que se faça uma análise sistemática do ordenamento jurídico brasileiro.

Pode-se dizer que, hoje, há três teses existentes que buscam endereçar esse problema e, ao final desta seção, delinear-se-á uma quarta alternativa. Inicialmente, diversos autores interpretaram o artigo 14 de forma restritiva, de modo que as únicas hipóteses autorizativas possíveis para se tratar dados de crianças — pessoas de até 12 anos incompletos — estariam em seu $\S 1^{\circ}$ e $\S 3^{\circ}$. Sendo assim, o agente de tratamento de dados deveria sempre requisitar o consentimento dos pais, tratar os dados para que eles fossem contatados ou tratar os dados para a proteção da criança. No que se refere aos adolescentes, seus dados deveriam ser tratados a partir das bases legais presentes no art. $7^{\circ}$ e 11 , desde que preservado o melhor interesse que também os abrange segundo o caput do art. 14, da LGPD.

Uma segunda tese está calcada na possibilidade de que todas as bases legais presentes no art. $7^{\circ}$ e no art. 11 poderiam ser utilizadas ordinariamente para o tratamento de dados tanto de crianças quanto de adolescentes, mas, no momento de sua aplicação, seria necessário fazer uma análise do melhor interesse, a partir do caso concreto. Em uma terceira via, defende-se que dados de crianças e adolescentes devem ser considerados dados sensíveis, a fim de que se aplique as bases legais do art. 11 e não as do art. $7^{\circ}$, da LGPD.

Todavia, acredita-se que uma análise aprofundada do ordenamento, que leve em consideração o sistema de proteção à criança e ao adolescente já existente, especialmente na Convenção sobre os Direitos da Criança (doravante Convenção) ${ }^{22}$, na Constituição Federal e no Estatuto da Criança e do Adolescente (ECA), deixaria claro que o legislador se equivocou

\footnotetext{
${ }^{22}$ BRASIL. Decreto n ${ }^{\circ} 99.710$, de 21 de novembro de 1990. Promulga a Convenção sobre os Direitos da Criança. Brasília, 1990. Disponível em: http://www.planalto.gov.br/ccivil_03/decreto/1990-1994/D99710.htm. Acesso em: 22 jan. 2021.
} 
ao apresentar o tema de maneira vaga. Nesse sentido, é preciso se valer desses instrumentos para endereçar o tema e identificar uma quarta via de interpretação, que ora se passa a propor.

Um primeiro passo para a compreensão da problemática é entender o que significa tratar dados a partir do melhor interesse. Sendo essa a chave mestra para qualquer tratamento de dados de crianças ou adolescentes, ela age como verdadeiro filtro em relação àquilo que estaria ou não adequado a esse sistema de proteção.

O Comitê sobre os Direitos da Criança, que tem como uma de suas funções a interpretação da Convenção, em seu Comentário Geral n. ${ }^{\circ} 14,{ }^{23}$ interpretou o art. 3, 1, da normativa, que trata justamente sobre o melhor interesse. Segundo o Comitê, este princípio visa a assegurar a fruição plena e efetiva de todos os direitos reconhecidos na Convenção, bem como o desenvolvimento global da criança, de modo a garantir sua integridade física, psicológica, moral e espiritual e a promover sua dignidade. Trata-se de conceito complexo, que, preferencialmente, deve ser analisado caso a caso. Contudo, nas decisões coletivas, como as que emanam do art. 14, da LGPD, o Comitê entende que o melhor interesse deve ser avaliado e determinado à luz das circunstâncias do grupo específico ou das crianças em geral. ${ }^{24}$

A fim de gerar consequências práticas a partir da interpretação desse conceito, ele pode ser entendido, segundo o Comitê, a partir de três vieses. Primeiramente, compreender-se-ia o melhor interesse como um direito fundamental, isto é, crianças têm o direito fundamental a que seu melhor interesse seja avaliado e constitua uma consideração primordial quando diferentes interesses estejam em jogo, bem como a garantia de que este direito será aplicado sempre que se tenha de tomar uma decisão que afete uma criança, um grupo de crianças ou as crianças em geral.

Em segundo lugar, ele pode ser compreendido como um princípio jurídico fundamentalmente interpretativo, o que significa dizer que se uma disposição jurídica estiver aberta a mais do que uma interpretação, deve ser escolhida a que efetivamente melhor satisfaça o melhor interesse da criança. Por fim, é entendido também como regra de procedimento:

\footnotetext{
${ }^{23}$ UN COMMITTEE ON THE RIGHTS OF THE CHILD. General comment No. 14 (2013) on the right of the child to have his or her best interests taken as a primary consideration (art . 3, para. 1). UN Doc CRC/C/GC/14. [s.1.], 2013. Disponível em: https://tbinternet.ohchr.org/_layouts/15/treatybodyexternal/Download.aspx?symbolno=CRC\%2fC\%2fGC\%2f14 \&Lang=en. Acesso em: 04 jan. 2021.

${ }^{24}$ UN COMMITTEE ON THE RIGHTS OF THE CHILD. General comment No. 14 (2013) on the right of the child to have his or her best interests taken as a primary consideration (art . 3, para. 1). UN Doc CRC/C/GC/14. [s.l.], 2013. Disponível em: https://tbinternet.ohchr.org/_layouts/15/treatybodyexternal/Download.aspx?symbolno=CRC $\% 2 \mathrm{fC} \% 2 \mathrm{fGC} \% 2 \mathrm{f} 14$ $\&$ Lang=en. Acesso em: 04 jan. 2021.
} 
sempre que é tomada uma decisão que afeta uma determinada criança, um grupo de crianças ou as crianças em geral, o processo de tomada de decisão deve incluir uma avaliação de seu possível impacto.

Compreendendo o melhor interesse como um direito fundamental, percebe-se que o art. 14 , em seus $\S \S 1^{\circ}$ e $3^{\circ}$, não é suficiente para concretizá-lo. Exemplo disso é o tratamento de dados de crianças para políticas públicas, no âmbito do direito à educação. ${ }^{25}$ Sendo a educação obrigatória no país, não seria possível se utilizar o consentimento dos pais, já que isso pressupõe uma escolha e autonomia por parte do titular de dados ou de seu responsável legal. Da mesma forma, as hipóteses presentes no $\S 3^{\circ}$ não se adequariam a essa situação. Nesse sentido, o art. $7^{\circ}$, III, torna-se essencial para suprir essa lacuna e cumprir o melhor interesse como direito fundamental.

O mesmo ocorre no tratamento de dados para a proteção da vida ou da incolumidade física (inciso VII) e para a tutela de sua saúde (inciso VIII) ${ }^{26}$, hipóteses autorizativas que definitivamente podem ser utilizadas para garantir o melhor interesse. Tendo em vista estes exemplos, esse exercício interpretativo deve ser feito com cada uma das bases legais do art. $7^{\circ}$ e 11. Percebe-se que a maior parte delas poderá garantir os direitos presentes na Convenção, na Constituição Federal e no ECA, desde que a forma do tratamento dos dados esteja ancorada ao melhor interesse. Deste modo, afasta-se, automaticamente, a primeira tese, segundo a qual as bases legais para tratamento de dados de crianças estariam presentes apenas no art. 14 .

Em contrapartida, ao se compreender o melhor interesse como direito fundamental e, também, como princípio interpretativo, duas bases legais presentes no art. $7^{\circ}$ se destacam como problemáticas: o legítimo interesse e a proteção ao crédito. Essas são bases legais extremamente flexíveis, o que permite que o agente reutilize dados para outras finalidades, sem que os titulares necessariamente tenham conhecimento. Isso pode colocar em xeque, por exemplo, a transparência necessária para se avaliar o melhor interesse em cada caso. Visto que os próprios agentes de tratamento poderiam interpretar o que ele significa, caberia à Autoridade Nacional

\footnotetext{
${ }^{25}$ Cf. FERNANDES, Elora Raad. Uso de Tecnologias na Educação Básica em temos de pandemia: reflexões sobre a proteção de dados de crianças. In: LIMA, Stephane. Educação, dados e plataformas: análise descritiva dos termos de uso dos serviços educacionais google e microsoft. São Paulo: Iniciativa Educação Aberta, 2020. p. 1415. Disponível em: https://zenodo.org/record/4005013\#.X0jaG6LQjIU. Acesso em: 23 jan. 2021.

${ }^{26}$ Sobre o tratamento de dados de crianças e adolescentes no âmbito da tutela da saúde, cf. FERNANDES, Elora Raad; CANTANHEDE, Cindyneia Ramos. Proteção de crianças e adolescentes por design: um debate necessário em meio à pandemia de covid-19. In: BIONI, Bruno R.; ZANATTA, Rafael A. F.; RIELLI, Mariana; VERGILI, Gabriela; FAVARO, Iasmine. Os dados e o vírus: pandemia, proteção de dados e democracia. pandemia, proteção de dados e democracia. São Paulo: Data Privacy Brasil, 2020. p. 73-81.
} 
de Proteção de Dados (ANPD) ou ao Judiciário uma análise apenas a posteriori - o que pode ser bastante arriscado tendo em vista, especialmente, os interesses inerentes ao setor privado, que nem sempre estão alinhados aos direitos fundamentais.

A hipótese autorizativa da proteção ao crédito revela-se ainda mais problemática, uma vez que o interesse do agente de tratamento, neste contexto, é intrinsecamente financeiro, o que não pode se sobrepor, em uma perspectiva de ponderação, à privacidade e à proteção dos dados de crianças e adolescentes, cuja tutela é essencial e instrumental para a concretização de outros direitos fundamentais. Destaca-se que essa base legal não existe, por exemplo, na Europa, tendo advindo diretamente da pressão do setor financeiro e de data brokers durante a tramitação dos projetos de lei que deram origem à LGPD. Em suma, ao se lançar mão do melhor interesse como direito fundamental e como princípio interpretativo, deve-se afastar, de plano, a aplicação dos incisos IX e $\mathrm{X}$ do art. $7^{\circ}$.

Uma controvérsia, nesse sentido, poderia surgir nos casos em que o legítimo interesse é utilizado para tratar dados com a finalidade de segurança e proteção. Exemplo disso ocorre na utilização de circuitos internos de câmeras, como nos bancos. Nessa circunstância, entretanto, seria possível se valer do $\S 3^{\circ}$ do próprio art. 14. De acordo com este dispositivo, sempre que for necessário para proteger a criança, bem como para contatar seus pais ou responsáveis legais, a coleta de dados poderá ocorrer independentemente de consentimento. Entende-se que isso pode ser estendido aos adolescentes, uma vez que a eles também se aplica o melhor interesse como direito fundamental e, com isso, a necessária proteção.

Até aqui, foi possível afastar as duas primeiras teses, restando uma análise mais aprofundada sobre a consideração dos dados de crianças e adolescentes como dados sensíveis e a consequente aplicação das bases legais do art. 11. Destaca-se, nessa linha, que essa interpretação possui uma vantagem intrínseca: o rol de bases legais presentes no art. 11 tem grande paralelismo com as o art. $7^{\circ}$ - retirando-se o legítimo interesse e a proteção ao crédito e adicionando-se o tratamento de dados para prevenção à fraude e à segurança do titular. Todavia, antes de se pensar apenas nas consequências de se reconhecer um dado como sensível, é preciso entender se todos os dados de crianças podem ser considerados, de fato, como sensíveis.

Preliminarmente, é necessário compreender que o rol de dados sensíveis, seja ele aberto ou fechado - discussão que ainda se prolonga na doutrina — inclui categorias de dados específicas e não titulares especiais de dados. Nesse sentido, são dados sensíveis, por exemplo, aqueles sobre origem racial ou étnica, convicção religiosa, opinião política, etc., conforme o art. 
$5^{\circ}$, II, da LGPD. Sendo assim, ao se permitir que a vulnerabilidade de crianças justifique o tratamento de seus dados como sensíveis, não seria o caso de estender esse entendimento também para dados de idosos e de pessoas com deficiência, por exemplo?

Em segundo lugar, a definição dos dados como sendo sensíveis está atrelada a seu potencial discriminatório, sendo o seu regime de proteção mais rigoroso. Eles se diferenciam dos dados comuns, por exemplo, nas bases legais permitidas para seu tratamento, na requisição de consentimento em destaque e na intensificação das medidas de segurança. Contudo, uma interpretação adequada do melhor interesse teria o potencial de proteger dados de crianças de forma muito mais ampla, vez que requer uma proteção integral dos direitos infanto-juvenis, não se atendo somente à não discriminação.

Por fim, ao se enquadrar o tratamento de dados de crianças e adolescentes sob a égide exclusiva do art. 11, perder-se-ia a chance de se criar uma camada extra de proteção em relação aos dados sensíveis de crianças e adolescentes, sendo estes considerados hipersensíveis. Nesse sentido, com base no melhor interesse, parece evidente que dados referentes à religião, orientação sexual e biometria dessas pessoas, a título de exemplo, devem ser protegidos com ainda mais rigor que os mesmos dados referentes a adultos. Levando-se em consideração a vulnerabilidade de crianças e adolescentes, o tratamento discriminatório pode ter efeitos bem mais severos na vida dessas pessoas.

Por essa perspectiva, pode-se pensar no tratamento de dados a partir do reconhecimento facial, principalmente para finalidades de vigilância em massa (identificação), que, além de ter o potencial de gerar discriminação, pode ainda violar diversos outros direitos fundamentais, como a liberdade de expressão e de associação. Assim, considera-se que o art. 11 e toda a construção teórica que o fundamenta, em conjunto com o art. 14, devem ser aplicados apenas quando se tratar de dados de crianças e de adolescentes que se encaixem no rol de dados sensíveis.

A partir dos desafios apresentados pelas três interpretações apontadas acima, é necessário e possível pensar em uma nova alternativa. Desse modo, levando em consideração os princípios estabelecidos na LGPD e em todo o ordenamento jurídico brasileiro, parece ser possível advogar que, para tratar dados de crianças e adolescentes poderiam ser aplicadas as bases legais previstas nos incisos I a VIII do art. $7^{\circ}$, da LGPD — desde que estejam sempre orientadas pelo melhor interesse. Além disso, deve-se considerar a base legal estabelecida no art. $14, \S 3^{\circ}$ e, especificamente em relação ao consentimento para tratamento de dados de crianças, deve-se aplicar a regra do art. $14, \S 1^{\circ}$. Por fim, quando a hipótese envolver dados 
sensíveis de crianças e adolescentes, a conjunção será do art. 14 com o art. 11, da mesma normativa. Em todas as situações, no entanto, um Relatório de Impacto à Proteção de Dados Pessoais será essencial para avaliar como o melhor interesse será aplicado em cada caso, o que será delineado na próxima seção.

\section{Relatório de Impacto à Proteção de Dados}

Ao se inspirar na legislação europeia de proteção de dados, a Lei Geral de Proteção de Dados Pessoais (LGPD) adotou, como um dos instrumentos de adequação à lei, o relatório de impacto à proteção de dados pessoais. Em seu art. $5^{\circ}$, XVII, a Lei o define como "documentação do controlador que contém a descrição dos processos de tratamento de dados pessoais que podem gerar riscos às liberdades civis e aos direitos fundamentais, bem como medidas, salvaguardas e mecanismos de mitigação de risco". Em outras palavras, eles são o resultado de uma avaliação de impacto anterior, que busca compreender a necessidade e a proporcionalidade de determinado tratamento e ajudar a gerir os riscos para os direitos e liberdades dele decorrentes ${ }^{27}$, apresentando uma intensa carga de prevenção de danos.

Devido à grande subjetividade existente nesse tipo de análise, mostra-se extremamente importante que sejam traçadas orientações que sirvam de guia aos agentes de tratamento, ${ }^{28}$ especialmente delimitando as situações nas quais esse relatório será obrigatório. Tendo em vista que a Autoridade Nacional de Proteção de Dados brasileira ainda está em processo de consolidação, revela-se possível e necessário pensar em casos de elaboração mandatória, a partir de suas especificidades e de uma análise sistemática do ordenamento brasileiro. Um deles é o tratamento de dados de crianças e adolescentes.

Em primeiro lugar, deve-se destacar que a análise de impacto a direitos de crianças e adolescentes de maneira mais ampla já é uma necessidade apresentada pelo próprio princípio do melhor interesse. Como já explicitado acima, uma das facetas do melhor interesse é seu entendimento como regra de procedimento, isto é, a demanda de que, em um processo de tomada de decisão que envolva uma criança, um grupo de crianças ou as crianças em geral, deve-se sempre incluir uma avaliação do possível impacto (positivo ou negativo) da decisão

\footnotetext{
${ }^{27}$ GRUPO DO ARTIGO 29. ${ }^{\circ}$ PARA A PROTEÇÃO DE DADOS. Orientações relativas à Avaliação de Impacto sobre a Proteção de Dados (AIPD) e que determinam se o tratamento é "suscetivel de resultar num elevado risco" para efeitos do Regulamento (UE) 2016/679. [s.1.], 2017. Disponível em: https://ec.europa.eu/newsroom/article29/item-detail.cfm?item_id=611236. Acesso em: 21 jan. 2021.

${ }^{28}$ GOMES, Maria Cecília Oliveira. Relatório de Impacto à Proteção de Dados: uma breve análise da sua definição e papel na lgpd. Revista do Advogado, São Paulo, n. 144, p. 6-15, nov. 2019.
} 
sobre ela(s). Nesse sentido, deve-se utilizar a avaliação para explicar como o melhor interesse foi considerado na decisão, em quais critérios ela se baseia e como foi realizada a ponderação do melhor interesse em relação a outras considerações. ${ }^{29}$

Essa avaliação deve levar em conta a idade e maturidade da criança (isto é, medidas diferentes devem ser tomadas, por exemplo, para crianças de 3 ou 10 anos), que se desenvolve ao longo do tempo. Assim, essas medidas devem ser revistas ou ajustadas com base nas necessidades físicas, emocionais, educacionais, entre outras, além de que possíveis cenários para o desenvolvimento infantil devem ser avaliados e analisados a curto e longo prazo. ${ }^{30}$

O já mencionado Comitê determina, no Comentário Geral n. $5,{ }^{31}$ a imprescindibilidade de um monitoramento e análise de impacto, por parte do Estado e de toda a sociedade, de decisões que impactem crianças e a concretização de seus direitos. No caso de análises mais amplas de impactos a direitos, já há modelos bem estruturados que podem ser utilizados como parâmetro, como é o caso do guia elaborado pela Unicef ${ }^{32}$. A mesma necessidade é apresentada pelo recém lançado Comentário Geral $n^{\circ} 25$ sobre os Direitos das Crianças em relação ao ambiente digital, que determina que

\begin{abstract}
Estados Partes devem exigir que o setor empresarial realize a devida diligência dos direitos da criança, em particular para realizar avaliações de impacto dos direitos da criança e divulgá-las ao público, com especial atenção aos impactos diferenciados e, às vezes, severos do ambiente digital sobre as crianças. Eles devem tomar medidas apropriadas para prevenir, monitorar, investigar e punir os abusos dos direitos da criança por parte das empresas. ${ }^{33}$
\end{abstract}

${ }^{29}$ UN COMMITTEE ON THE RIGHTS OF THE CHILD. General comment No. 14 (2013) on the right of the child to have his or her best interests taken as a primary consideration (art . 3, para. 1). UN Doc CRC/C/GC/14. $\quad$ [s.l.], 2013. Disponível em: https://tbinternet.ohchr.org/_layouts/15/treatybodyexternal/Download.aspx ?symbolno=CRC\%2fC\%2fGC\%2f14 $\&$ Lang=en. Acesso em: 04 jan. 2021.

${ }^{30}$ HOF, Simone van Der; LIEVENS, Eva. The Importance of Privacy by Design and Data Protection Impact Assessments in Strengthening Protection of Children's Personal Data Under the GDPR. Communications Law, [s. 1], v. 23, n. 1, 2018. Disponível em: https://papers.ssrn.com/sol3/papers.cfm?abstract_id=3107660. Acesso em: 10 out. 2020.

${ }^{31}$ UN COMMITTEE ON THE RIGHTS OF THE CHILD. General Comment $n .^{\circ}$ 5: General measures of implementation of the Convention on the Rights of the Child (arts. 4, 42 and 44, para. 6). UN Doc CRC/GC/2003/527. [s.1.], 2003. 2 Disponível em: https://docstore.ohchr.org/SelfServices/FilesHandler.ashx?enc=6QkG1d\%2FPPRiCAqhKb7yhsiQq18gX5Zxh0c QqSRzx6Zd2\%2FQRsDnCTcaruSeZhPr2vUevjbn6t6GSi1fheVp\%2Bj5HTLU2Ub\%2FPZZtQWn0jExFVnWuhi BbqgAj0dWBoFGbK0c. Acesso em: 04 jan. 2021.

${ }^{32}$ UNICEF; DANISH INSTITUTE FOR HUMAN RIGHTS. Children's Rights in Impact Assessments. UN Doc CRC/GC/2003/527. [s.1.], 2013. Disponível em: https://sites.unicef.org/csr/assessments.html. Acesso em: 04 jan. 2021.

${ }^{33}$ COMITÊ SOBRE OS DIREITOS DA CRIANÇA. Comentário Geral No. 25 (2021) sobre os Direitos das Crianças em relação ao ambiente digital. UN Doc CRC/C/GC/25. [s.1.], 2021. Tradução não oficial do Instituto Alana do inglês para o português. Disponível em: https://criancaeconsumo.org.br/wpcontent/uploads/2021/04/comentario-geral-n-25-2021.pdf. Acesso em: 20 abr. 2021, para. 38. 
Além de o Brasil estar obrigado a cumprir as determinações da Convenção, a necessidade de relatórios de impacto na proteção de dados de crianças e adolescentes já é algo aventado na Europa e consolidado nas legislações mais avançadas neste tema no mundo, em especial no Reino Unido e na Irlanda.

Embora o GDPR não traga explicitamente essa determinação, o Grupo de Trabalho do Artigo 29. ${ }^{\circ}$ para a Proteção de Dados, ao interpretar o regulamento e apresentar orientações sobre o tema,${ }^{34}$ traz como exemplo de situação que exigiria tal documentação o tratamento de dados relativos a titulares de dados vulneráveis (considerando 75). Isso inclui os dados de crianças, devido ao acentuado desequilíbrio de poder entre os titulares dos dados e o agente de tratamento.

Destaca-se, também, o Reino Unido, que foi pioneiro na previsão, dentro de sua lei de proteção de dados (Data Protection Act), da necessidade específica de o Information Commissioner's Office (ICO), sua autoridade nacional de proteção de dados, elaborar um código de práticas que contivesse orientações sobre padrões de design tecnologicamente neutros e adequados às diferentes idades. O Age Appropriate Design Code ${ }^{35} \mathrm{ou}$, simplesmente, Children's Code, inteiramente baseado na Convenção, apresenta 15 padrões de design cumulativos e interligados para fornecer proteção integrada, permitindo que crianças explorarem, aprenderam e joguem online de maneira segura. O padrão 2 é, justamente, a necessidade de se elaborar um relatório de impacto à proteção de dados. A autoridade destaca que não se trata de definir se o serviço é realmente de alto risco, mas de uma análise de indicadores potenciais de alto risco. Nesse sentido, entende que o contexto dos serviços online dentro do escopo do código, isto é, que tratam dados de crianças e adolescentes, inevitavelmente envolve um tratamento que pode resultar em um alto risco para os direitos e liberdades de crianças e adolescentes.

Da mesma maneira entende a Data Protection Commission (DPC), da Irlanda, que recentemente lançou um documento bastante semelhante ao da ICO: o Fundamentals for a

\footnotetext{
${ }^{34}$ GRUPO DO ARTIGO 29. ${ }^{\circ}$ PARA A PROTEÇÃO DE DADOS. Orientações relativas à Avaliação de Impacto sobre a Proteção de Dados (AIPD) e que determinam se o tratamento é "suscetivel de resultar num elevado risco" para efeitos do Regulamento (UE) 2016/679. [s.1.], 2017. Disponível em: https://ec.europa.eu/newsroom/article29/item-detail.cfm?item_id=611236. Acesso em: 21 jan. 2021.

35 REINO UNIDO. INFORMATION COMMISSIONER'S OFFICE. Age appropriate design: a code of practice for online services. [s.1.], 2020. Disponível em: https://ico.org.uk/for-organisations/guide-to-data-protection/keydata-protection-themes/age-appropriate-design-a-code-of-practice-for-online-services/. Acesso em: 04 jan. 2021.
} 
child-oriented approach to data processing ${ }^{36}$. A DPC entende, também, que o melhor interesse requer que um relatório de impacto à proteção de dados seja sempre elaborado quando os serviços de determinada organização seja direcionado/destinado a crianças ou quando possam ser por elas acessados. Essa análise deverá considerar as diferentes idades, capacidades e necessidades de desenvolvimento, bem como os riscos reais e potenciais decorrentes do processamento de dados para a saúde, o bem-estar e os interesses gerais da criança, incluindo danos sociais, mentais, físicos e financeiros.

Percebe-se, portanto, que as obrigações internacionais assumidas pelo Brasil, bem como o sistema de proteção de crianças e adolescentes no país e as melhores práticas internacionais demandam uma obrigatoriedade de elaboração do relatório de impacto à proteção de dados de crianças e adolescentes. Nesse sentido, é imperativo que a ANPD siga o mesmo caminho e adote, em sua interpretação sobre a matéria, este entendimento.

\section{A minimização na coleta dos dados segundo o artigo $14, \S^{\circ}$}

O último desafio interpretativo que se busca enfrentar no presente trabalho é aquele relativo ao parágrafo quarto do artigo 14, que assim dispõe: “[o]s controladores não deverão condicionar a participação dos titulares de que trata o $\S 1^{\circ}$ deste artigo em jogos, aplicações de internet ou outras atividades ao fornecimento de informações pessoais além das estritamente necessárias à atividade.”

Para compreender o real alcance desta norma, necessário fazer menção a importante princípio trazido pela LGPD em seu artigo $6^{\circ}$, inciso III: a necessidade, que nas palavras do legislador significa "limitação do tratamento ao mínimo necessário para a realização de suas finalidades, com abrangência dos dados pertinentes, proporcionais e não excessivos em relação às finalidades do tratamento de dados." Este princípio, pode ser resumido na seguinte formulação: não tratar dados além do necessário. Nesse sentido, o tratamento poderá ser considerado abusivo, mesmo que seja fornecido o consentimento por parte dos responsáveis ${ }^{37}$ ou seja utilizada outra base legal válida.

Tal parágrafo se revela, portanto, como uma concretização do princípio da necessidade,

\footnotetext{
36 IRLANDA. DATA PROTECTION COMMISSION. Fundamentals for a child-oriented approach to data processing. [s.1.], 2020. Disponível em: https://www.dataprotection.ie/en/news-media/consultations/childrenfront-and-centre-fundamentals-child-oriented-approach-data-processing. Acesso em: 04 jan. 2021.

37 TEFFÉ, Chiara Spadaccini de. Tratamento de dados pessoais de crianças e adolescentes: considerações sobre o artigo 14 da LGPD. O tratamento de dados pessoais sensíveis. In: MULHOLLAND, Caitlin (org.). A LGPD e o novo marco normativo no Brasil. Porto Alegre: Arquipélago, 2020, p. 171.
} 
na medida em que deve haver minimização não só do tratamento como, primeiramente, da própria coleta dos dados coletados reputados como não essenciais à atividade desenvolvida, o que não deve prescindir, como visto, de Relatórios de Impacto.

Esta regra objetiva "afastar as políticas de 'tudo ou nada', em que o usuário ou aceita todas as disposições do serviço ou não pode utilizá-lo", 38 tão comuns em contratações eletrônicas de aplicativos, que tendem a ser sempre contratos de adesão. Como exemplo de aplicação prática desta norma, pense-se que para que uma criança possa criar uma conta em determinado aplicativo não se deve exigir mais do que o mínimo indispensável para o jogo. Ou seja, a coleta de dados deve ser reservada ao melhoramento da jogabilidade, não sendo lícito utilizá-los, por exemplo, para municiar, eventualmente, publicidade.

Embora concretize os princípios acima mencionados, a norma vai além, ao empregar a expressão "estritamente necessárias", o que parece ser um aprofundamento dos princípios gerais. Se essa vedação já é importante para pessoas adultas sujeitas a contratos de adesão em que fornecem seus dados em troca do acesso a funcionalidades, mais ainda deve ser a proteção conferida a essas pessoas em desenvolvimento, haja vista a ínsita vulnerabilidade e a gravidade dos danos que podem advir do tratamento de seus dados, como já amplamente demonstrado ao longo deste trabalho. ${ }^{39}$

Como esclarecem Pedro Hartung, Isabella Henriques e Marina Pita, a ratio da norma é que:

ainda que não haja consentimento parental para o tratamento de dados de crianças e adolescentes até 16 anos de idade incompletos, tais indivíduos não podem ser privados da participação em jogos ou aplicações. Tal dispositivo ressalta o fato de que o objetivo do consentimento parental não é privar crianças e adolescentes do uso das ferramentas digitais disponíveis, mas garantir que, ao utilizá-las, seus dados não sejam tratados ou processados sem o devido consentimento de seus responsáveis legais. ${ }^{40}$

\footnotetext{
${ }^{38}$ TEFFÉ, Chiara Spadaccini de. Tratamento de dados pessoais de crianças e adolescentes: considerações sobre o artigo 14 da LGPD. O tratamento de dados pessoais sensíveis. In: MULHOLLAND, Caitlin (org.). A LGPD e o novo marco normativo no Brasil. Porto Alegre: Arquipélago, 2020, p. 171.

39 " [A] coleta de DP de crianças possui um caráter certamente mais sensível se comparada à obtenção de informações de adultos, já que os mecanismos de manipulação do comportamento infantil podem surtir mais efeitos nesse público. Da mesma forma, as consequências (como a possibilidade de discriminação) podem ser mais expressivas e duradouras quando atingem pessoas mais novas. Dessa maneira, os termos de uso no ambiente digital, inclusive naquele concebido para crianças e adolescentes, em nome da proteção do consentimento e como forma de reduzir a vulnerabilidade, deveriam buscar métodos de aproximação entre o aceite digital e o consentimento informado. As informações e os termos contratuais, mais do que disponíveis, devem ser redigidos de modo a serem lidos e compreendidos pelos usuários, além de ser desejável, inclusive, que haja mecanismos para esclarecimento de dúvidas e de constituição de um diálogo.” (EBERLIN, Fernando Büscher von Teschenhausen. Direitos da Criança na Sociedade da Informação: ambiente digital, privacidade e dados pessoais. São Paulo: Thomson Reuters Brasil, 2020, p. 185).

${ }^{40}$ HARTUNG, Pedro; HENRIQUES, Isabella; PITA, Marina. A proteção de dados pessoais de crianças e adolescentes. In: DONEDA, Danilo; MENDES, Laura Schertel; SARLET, Ingo Wolfgang; RODRIGUES JR.,
} 
Segundo Chiara de Teffé, o dispositivo mostra que a Lei é "refratária à requisição excessiva de dados de crianças em serviços de divertimento e entretenimento." ${ }^{41}$ Nada obstante, a Lei não parece ter limitado a aplicação da regra contida neste parágrafo a tais serviços, gozando de abrangência mais ampla. Deve-se destacar, ainda, que a restrição do tratamento de dados para esses fins deve ser balanceada com a necessidade de se tratar dados para verificação da idade. Essa verificação é essencial para se averiguar a necessidade do consentimento dos pais e para a aplicação de uma tutela mais rígida através da proteção por design. ${ }^{42}$ Isso porque, a um só tempo, a exigência de menos dados para proteção das crianças que lhes parece benéfica num primeiro olhar, pode vir a se tornar maléfica também, na medida em que com menos dados, passa a ser mais difícil apurar, de fato, se houve participação parental na formação daquele consentimento e se ele será, por consequência, válido e eficaz.

Em resumo, apesar de derivar do princípio da necessidade já positivado no art. $6^{\circ}$, o parágrafo $4^{\circ}$, do art 14 , da LGPD é mais rígido. Isso porque não basta mencionar outras finalidades no negócio jurídico a ser estabelecido para que se colete dados extras às finalidades precípuas da aplicação. No caso de adultos, a LGPD determina que o princípio da necessidade está intimamente ligado ao da finalidade: desde que seja uma finalidade legítima, basta anunciála de forma transparente, encontrar uma base legal adequada e tratar os dados necessários a ela. No caso de crianças e adolescentes, é necessário se abster de finalidades outras que não digam respeito ao funcionamento básico da aplicação. Foi este um passo importantíssimo para que os dados de crianças e adolescentes possam ser tratados apenas em seu melhor interesse, especialmente tendo em vista o modelo de negócios predominante atualmente, baseado na publicidade direcionada.

Otavio Luiz; BIONI, Bruno (coords). Tratado de Proteção de Dados Pessoais. Rio de Janeiro: Forense, 2021, p. 214

${ }^{41}$ TEFFÉ, Chiara Spadaccini de. Tratamento de dados pessoais de crianças e adolescentes: considerações sobre o artigo 14 da LGPD. O tratamento de dados pessoais sensíveis. In: MULHOLLAND, Caitlin (org.). A LGPD e o novo marco normativo no Brasil. Porto Alegre: Arquipélago, 2020, p. 171.

${ }^{42}$ Nesse sentido, a 5Rights Foundation propõe, em recente publicação, 11 padrões a serem respeitados quando se trata de verificação de idade no ambiente digital: "1. A verificação da idade deve preservar a privacidade; 2. A verificação da idade deve ser proporcional ao risco e ao propósito; 3 . A verificação da idade deve ser fácil para a criança utilizar; 4. A verificação da idade deve melhorar as experiências das crianças, não apenas restringi-las; 5. Provedores de verificação de idade devem oferecer um alto nível de segurança; 6. Provedores de verificação de idade devem oferecer caminhos para contestar e corrigir; 7. A verificação da idade deve ser acessível e inclusiva; 8. A verificação da idade deve ser transparente e responsável; 9. A verificação da idade deve antecipar que as crianças nem sempre dizem a verdade; 10. A verificação da idade deve seguir os padrões acordados; 11. A verificação da idade deve respeitar direitos" (5RIGHTS FOUNDATION.. 'But how do they know it is a child?': age assurance in the digital world. [s.l.], 2021. Disponível em: https://5rightsfoundation.com/in-action/but-howdo-they-know-it-is-a-child-age-assurance-in-the-digital-world.html. Acesso em: 31 mar. 2021, tradução nossa.) 


\section{Conclusão}

Por ter sido concebida como uma lei geral, cujo escopo abrange os setores público e privado e o tratamento de dados online e offline, a LGPD demanda esforço de interpretação mais robusto por parte da doutrina, do Judiciário e, principalmente, da ANPD. Como se procurou demonstrar, especialmente no que concerne a crianças e adolescentes, a Lei é bastante limitada, não apresentando detalhes essenciais para a concretização do melhor interesse no tratamento dos dados desses sujeitos, o que é motivo de inquietantes dúvidas e desafios interpretativos

A partir disso, este artigo teve como objetivo apresentar exegeses possíveis para alguns de seus dispositivos, levando sempre em consideração o ordenamento jurídico brasileiro de forma holística, com especial atenção para o arcabouço protetivo que vem sendo construído desde a promulgação da Convenção e do ECA. Em um primeiro momento, discutiu-se as polêmicas em torno do consentimento estabelecido no parágrafo primeiro do artigo 14, buscando-se compreender se o legislador definiu, de fato, na LGPD, hipótese de capacidade especial e como a autoridade parental deve ser utilizada em benefício do melhor interesse dos filhos.

Em seguida, adentrou-se nas controversas questões relacionadas às bases legais possivelmente aplicáveis ao tratamento de dados de crianças e adolescentes, defendendo-se que o melhor interesse deve servir de filtro na aplicação dos arts. $7^{\circ}$ e 11 e que as hipóteses autorizativas do legítimo interesse e da proteção ao crédito não poderiam ser utilizadas a priori. Debateu-se, ainda, a necessidade de se elaborar, em todas as ocasiões em que dados de crianças e adolescentes sejam tratados, Relatórios de Impacto à Proteção de Dados, que servirão como instrumentos essenciais na verificação da consideração do melhor interesse pelo agente de tratamento. Por fim, procurou-se demonstrar como o parágrafo $4^{\circ}$, do art. 14 trouxe um nível de tutela ainda mais rigoroso quando da aplicação do princípio da necessidade ao tratamento de dados dessas pessoas.

Como se pode notar, a tutela da personalidade - em especial da privacidade e dos dados pessoais - da criança e do adolescente, reveste-se de caráter peculiar e mais intenso, dada a condição de pessoas ainda em desenvolvimento. Diante das omissões e controvérsias postas pela Lei Geral de Proteção de Dados Pessoais nessa matéria, urge à doutrina, ao Judiciário e à ANPD concretizar, a partir do arcabouço normativo advindo da Convenção, do ECA e do 
Código Civil, o preenchimento de lacunas e a superação de inquietações, tendo a unidade e a sistematicidade do ordenamento como premissas inafastáveis, reportando-se sempre à matriz agregadora da Constituição da República e sua axiologia. Só assim será possível garantir a tutela da pessoa humana em desenvolvimento não apenas no mundo offline, como também diante de um mundo cada vez mais conectado. É papel dos pais, do setor privado e do Estado garantir que isso seja possível.

\section{REFERÊNCIAS}

5RIGHTS FOUNDATION.. 'But how do they know it is a child?': age assurance in the digital world. [s.l.], 2021. Disponível em: https://5rightsfoundation.com/in-action/but-how-do-theyknow-it-is-a-child-age-assurance-in-the-digital-world.html. Acesso em: 31 mar. 2021,

BARASSI, Veronica. Child $\mid$ Data $\mid$ Citizen: how tech companies are profiling us from before birth. Cambridge: Mit Press, 2020.

BLUM-ROSS, Alicia; LIVINGSTONE, Sonia. "Sharenting," parent blogging, and the boundaries of the digital self. Popular Communication, [s.l.], v. 15, n. 2, p. 110-125, 3 abr. 2017. Informa UK Limited. http://dx.doi.org/10.1080/15405702.2016.1223300.

BRASIL. Decreto $\mathrm{n}^{\circ}$ 99.710, de 21 de novembro de 1990. Promulga a Convenção sobre os Direitos da Criança. Brasília, 1990. Disponível em: http://www.planalto.gov.br/ccivil_03/decreto/1990-1994/D99710.htm. Acesso em: 22 jan. 2021.

BROSCH, Anna. When the child is born into the internet: sharenting as a growing trend among parents on facebook. The New Educational Review, [s.1.], v. 43, n. 1, p. 225-235, 31 mar. 2016. Wydawnictwo Adam Marszalek. http://dx.doi.org/10.15804/tner.2016.43.1.19.

DONEDA, Danilo. Da privacidade à proteção de dados pessoais, Rio de Janeiro: Renovar, 2006.

COMITÊ SOBRE OS DIREITOS DA CRIANÇA. Comentário Geral No. 25 (2021) sobre os Direitos das Crianças em relação ao ambiente digital. UN Doc CRC/C/GC/25. [s.1.], 2021. Tradução não oficial do Instituto Alana do inglês para o português. Disponível em: https://criancaeconsumo.org.br/wp-content/uploads/2021/04/comentario-geral-n-25-2021.pdf. Acesso em: 20 abr. 2021

EBERLIN, Fernando Büscher von Teschenhausen. Direitos da Criança na Sociedade da Informação: ambiente digital, privacidade e dados pessoais. São Paulo: Thomson Reuters Brasil, 2020.

EBERLIN, Fernando Büscher von Teschenhausen. Sharenting, liberdade de expressão e privacidade de crianças no ambiente digital: o papel dos provedores de aplicação no cenário jurídico brasileiro. Revista Brasileira de Políticas Públicas, [s.1.], v. 7, n. 3, p. 256-274, 6 fev. 2018. Centro de Ensino Unificado de Brasília. http://dx.doi.org/10.5102/rbpp.v7i3.4821. 
FERNANDES, Elora Raad; CANTANHEDE, Cindyneia Ramos. Proteção de crianças e adolescentes por design: um debate necessário em meio à pandemia de covid-19. In: BIONI, Bruno R.; ZANATTA, Rafael A. F.; RIELLI, Mariana; VERGILI, Gabriela; FAVARO, Iasmine. Os dados e o vírus: pandemia, proteção de dados e democracia. pandemia, proteção de dados e democracia. São Paulo: Data Privacy Brasil, 2020. p. 73-81.

FERNANDES, Elora Raad. Direitos de crianças e adolescentes por design: uma agenda regulatória para a ANPD. In: LATERÇA, Priscilla Silva; FERNANDES, Elora; TEFFÉ, Chiara de; BRANCO, Sérgio. Privacidade e Proteção de Dados de Crianças e Adolescentes. Rio de Janeiro: Obliq, 2021.

FERNANDES, Elora. Tratamento de dados de adolescentes no Brasil e a necessária proteção de direitos por design. In: Instituto de Tecnologia e Sociedade (ITS). Trabalhos finais do Grupo de Pesquisa 2020. Disponível em em: https://itsrio.org/wpcontent/uploads/2020/10/Tratamento-de-dados-de-adolescentes-no-Brasil-e-a-necessáriaproteção-de-direitos-por-design_Elora_Fernandes.pdf

FERNANDES, Elora Raad. Uso de Tecnologias na Educação Básica em temos de pandemia: reflexões sobre a proteção de dados de crianças. In: LIMA, Stephane. Educação, dados e plataformas: análise descritiva dos termos de uso dos serviços educacionais google e microsoft. São Paulo: Iniciativa Educação Aberta, 2020. p. 14-15. Disponível em: https://zenodo.org/record/4005013\#.X0jaG6LQjIU. Acesso em: 23 jan. 2021.

GOMES, Maria Cecília Oliveira. Relatório de Impacto à Proteção de Dados: uma breve análise da sua definição e papel na lgpd. Revista do Advogado, São Paulo, n. 144, p. 6-15, nov. 2019.

GRUPO DO ARTIGO 29. PARA A PROTEÇÃO DE DADOS. Orientações relativas à Avaliação de Impacto sobre a Proteção de Dados (AIPD) e que determinam se o tratamento é "suscetivel de resultar num elevado risco" para efeitos do Regulamento (UE) 2016/679. [s.1.], 2017. Disponível em: https://ec.europa.eu/newsroom/article29/itemdetail.cfm?item_id=611236. Acesso em: 21 jan. 2021.

HOF, Simone van Der; LIEVENS, Eva. The Importance of Privacy by Design and Data Protection Impact Assessments in Strengthening Protection of Children's Personal Data Under the GDPR. Communications Law, [s. 1], v. 23, n. 1, 2018. Disponível em: https://papers.ssrn.com/sol3/papers.cfm?abstract_id=3107660. Acesso em: 10 out. 2020.

IRLANDA. DATA PROTECTION COMMISSION. Fundamentals for a child-oriented approach to data processing. [s.1.], 2020. Disponível em: https://www.dataprotection.ie/en/news-media/consultations/children-front-and-centrefundamentals-child-oriented-approach-data-processing. Acesso em: 04 jan. 2021.

ITÁLIA. GARANTE PER LA PROTEZIONE DEI DATI PERSONALI. Tik Tok, a rischio la privacy dei minori: il Garante avvia il procedimento contro il social network, il Garante privacy dispone il blocco del social. 2021. Disponível em: https://www.garanteprivacy.it/web/guest/home/docweb/-/docweb-display/docweb/9508923. Acesso em: 12 fev. 2021.

ITÁLIA. GARANTE PER LA PROTEZIONE DEI DATI PERSONALI. Tik Tok: dopo il caso 
della bimba di Palermo, il Garante privacy dispone il blocco del social. 2021. Disponível em: https://www.garanteprivacy.it/web/guest/home/docweb/-/docweb-display/docweb/9524224. Acesso em: 12 fev. 2021.

ITALY blocks TikTok for certain users after death of girl allegedly playing 'choking' game. The Guardian. [s.l.]. 23 jan. 2021. Disponível em: https://www.theguardian.com/world/2021/jan/23/italy-blocks-tiktok-for-certain-users-afterdeath-of-girl-allegedly-playing-choking-game. Acesso em: 12 fev. 2021.

HARTUNG, Pedro; HENRIQUES, Isabella; PITA, Marina. A proteção de dados pessoais de crianças e adolescentes. In: DONEDA, Danilo; MENDES, Laura Schertel; SARLET, Ingo Wolfgang; RODRIGUES JR., Otavio Luiz; BIONI, Bruno (coords). Tratado de Proteção de Dados Pessoais. Rio de Janeiro: Forense, 2021.

MEDON, Filipe. (Over)sharenting: a superexposição da imagem e dos dados da criança na internet e o papel da autoridade parental. In: TEIXEIRA, Ana Carolina Brochado; DADALTO, Luciana. Autoridade Parental: dilemas e desafios contemporâneos. Indaiatuba: Editora Foco, 2021, 2. ed.

REINO UNIDO. INFORMATION COMMISSIONER'S OFFICE. Age appropriate design: a code of practice for online services. [s.l.], 2020. Disponível em: https://ico.org.uk/fororganisations/guide-to-data-protection/key-data-protection-themes/age-appropriate-design-acode-of-practice-for-online-services/. Acesso em: 04 jan. 2021.

SCHREIBER, Anderson. Proteção de dados no Brasil e na Europa. Carta Forense. [s.1.]. 5 set. 2018. Disponível em: http://www.cartaforense.com.br/conteudo/colunas/protecao-de-dadospessoais-no-brasil-e-na-europa/18269. Acesso em: 13 fev. 2021.

SHMUELI, Benjamin; BLECHER-PRIGAT, Ayelet. Privacy for Children. Columbia Human Rights Law Review, [s.1.], v. 42, p. 759-795, 2011. Disponível em: https://papers.ssrn.com/sol3/papers.cfm?abstract_id=1746540. Acesso em: 13 fev. 2021.

STEINBERG, Stacey. Growing up shared: how parents can share smarter on social media and what you can do to keep your family safe in a no-privacy world. Naperville: Sourcebooks, 2020

TEFFÉ, Chiara Spadaccini de. Tratamento de dados pessoais de crianças e adolescentes: considerações sobre o artigo 14 da LGPD. O tratamento de dados pessoais sensíveis. In: MULHOLLAND, Caitlin (org.). A LGPD e o novo marco normativo no Brasil. Porto Alegre: Arquipélago, 2020.

TEIXEIRA, Ana Carolina Brochado; MEDON, Filipe. A hipersexualização infanto-juvenil na internet e o papel dos pais: liberdade de expressão, autoridade parental e melhor interesse da criança. No prelo.

TEIXEIRA, Ana Carolina Brochado. NERY, Maria Carla Moutinho. Vulnerabilidade digital de crianças e adolescentes: a importância da autoridade parental para uma educação nas redes. In: EHRHARDT JR., Marcos; LOBO, Fabíola (orgs.). Vulnerabilidade e sua compreensão no direito brasileiro. Indaiatuba: Foco, 2021 
TEIXEIRA, Ana Carolina Brochado; RETTORE, Anna Cristina de Carvalho. A autoridade parental e o tratamento de dados pessoais de crianças e adolescentes. In: TEPEDINO, Gustavo; FRAZÃO, Ana; OLIVA, Milena Donato (coords.). Lei Geral de Proteção de Dados Pessoais e suas repercussões no Direito Brasileiro. São Paulo: Thomson Reuters Brasil, 2019.

TEPEDINO, Gustavo; MEDON, Filipe. A superexposição de crianças por seus pais na internet e o direito ao esquecimento. No prelo.

TEPEDINO, Gustavo; TEFFÉ, Chiara Spadaccini de. Consentimento e proteção de dados pessoais na LGPD. In: TEPEDINO, Gustavo; FRAZÃO, Ana; OLIVA, Milena Donato (coords.). Lei Geral de Proteção de Dados Pessoais e suas repercussões no Direito Brasileiro. São Paulo: Thomson Reuters Brasil, 2019.

UN COMMITTEE ON THE RIGHTS OF THE CHILD. General Comment $n .^{\circ}$ 5: General measures of implementation of the Convention on the Rights of the Child (arts. 4, 42 and 44, para. 6). UN Doc $\mathrm{CRC} / \mathrm{GC} / 2003 / 527$. [s.1.], 2003. Disponível em: https://docstore.ohchr.org/SelfServices/FilesHandler.ashx?enc=6QkG1d\%2FPPRiCAqhKb7y hsiQq18gX5Zxh0cQqSRzx6Zd2\%2FQRsDnCTcaruSeZhPr2vUevjbn6t6GSi1fheVp\%2Bj5HT LU2Ub\%2FPZZtQWn0jExFVnWuhiBbqgAj0dWBoFGbK0c. Acesso em: 04 jan. 2021.

UN COMMITTEE ON THE RIGHTS OF THE CHILD. General comment No. 14 (2013) on the right of the child to have his or her best interests taken as a primary consideration (art . 3, para. 1). UN Doc CRC/C/GC/14. [s.l.], 2013. Disponível em: https://tbinternet.ohchr.org/_layouts/15/treatybodyexternal/Download.aspx?symbolno=CRC\% 2fC\%2fGC\%2f14\&Lang=en. Acesso em: 04 jan. 2021.

UNICEF; DANISH INSTITUTE FOR HUMAN RIGHTS. Children's Rights in Impact Assessments. UN Doc CRC/GC/2003/527. [s.1.], 2013. Disponível em: https://sites.unicef.org/csr/assessments.html. Acesso em: 04 jan. 2021.

Recebido em: 09/06/2021

$1^{\circ}$ parecer em: $14 / 06 / 2021$

$2^{\circ}$ parecer em: 29/07/2021 